\title{
BCOR Gene Mutation
}

National Cancer Institute

\section{Source}

National Cancer Institute. BCOR Gene Mutation. NCI Thesaurus. Code C153113.

A change in the nucleotide sequence of the BCOR gene. 